\title{
Fibrin sealant promotes migration and proliferation of human articular chondrocytes: Possible involvement of thrombin and protease-activated receptors
}

\author{
YAOWANUJ KIRILAK ${ }^{1 *}$, NATHAN J. PAVLOS ${ }^{1 *}$, CRAIG R. WILLERS ${ }^{1}$, \\ RENZHI HAN ${ }^{1}$, HAOTIAN FENG ${ }^{1}$, JIAKE XU ${ }^{1}$, NITHIANANTHAN ASOKANANTHAN ${ }^{2}$, \\ GEOFFREY A. STEWART ${ }^{2,4}$, PETER HENRY ${ }^{3}$, DAVID WOOD ${ }^{1}$ and MING H. ZHENG ${ }^{1}$ \\ ${ }^{1}$ School of Surgery and Pathology (Orthopaedics), ${ }^{2}$ School of Biomedical and Chemical Sciences (Microbiology), \\ ${ }^{3}$ School of Medicine and Pharmacology (Pharmacology), The University of Western Australia, 35 Stirling \\ Highway, Crawley WA 6009; ${ }^{4}$ Western Australian Institute for Medical Research, Australia
}

Received October 31, 2005; Accepted December 5, 2005

\begin{abstract}
Fibrin sealant (FS), a biological adhesive material, has been recently recommended as an adjunct in autologous chondrocyte implantation (ACI). While FS has been shown to possess osteoinductive potential, little is known about its effects on chondrogenic cells. In this study, we assessed the bioactivity of FS (Tissee ${ }^{\circledR}$ ) on the migration and proliferation of human articular chondrocytes in vitro. Using a co-culture assay to mimic matrix-induced ACI (MACI), chondrocytes were found to migrate from collagen membranes towards FS within $12 \mathrm{~h}$ of culture, with significant migratory activity evident by $24 \mathrm{~h}$. In addition, 5-bromo-2'-deoxyuridine (BrdU) incorporation experiments revealed that thrombin, the active component of the tissue glue, stimulated chondrocyte proliferation, with maximal efficacy observed at $48 \mathrm{~h}$ poststimulation (1-10 U/ml). In an effort to elucidate the molecular mechanisms underlying these thrombin-induced effects, we examined the expression and activation of protease-activated receptors (PARs), established thrombin receptors. Using a combination of RT-PCR and immunohistochemistry, all four PARs were detected in human chondrocytes, with PAR-1 being the major isoform expressed. Moreover, thrombin and
\end{abstract}

Correspondence to: Professor Ming-Hao Zheng, Unit of Orthopaedics, School of Surgery and Pathology, University of Western Australia, 2nd Floor M-block QEII Medical Centre, Nedlands 6009, Australia

E-mail: zheng@cyllene.uwa.edu.au

${ }^{*}$ Contributed equally

Key words: fibrin sealant, thrombin, autologous chondrocyte implantation, calcium mobilization, collagen membrane, proteaseactivated receptors a PAR-1, but not other PAR-isotype-specific peptide agonists, were found to induce rapid intracellular $\mathrm{Ca}^{2+}$ responses in human chondrocytes in calcium mobilization assays. Together, these data demonstrate that FS supports both the migration and proliferation of human chondrocytes. We propose that these effects are mediated, at least in part, via thrombininduced PAR-1 signalling in human chondrocytes.

\section{Introduction}

Fibrin sealants (FSs) have long been utilised as an adjunct in a variety of surgical procedures to promote hemostasis and tissue sealing (1-4). In orthopaedics, FSs are used as a tissue adhesive for the fixation of osteochondral fragments and fractures (5), in spinal surgery (6), and securing perichondral grafts (7). More recently, fibrin preparations have been employed as biological vehicles for delivering chondrocytes directly to cartilage defects in order to stimulate repair processes, however with contradicting outcomes reported in the literature. Studies by Homminga et al demonstrated that chondrocytes encapsulated in FS retained their morphology and actively synthesised matrix suggesting that the adhesive served an effective matrice (8). Similarly, Hendrickson et al reported that FS-bound allogenic chondrocyte grafts displayed significantly higher glycosaminoglycan and collagen II content 8 months post-implantation (9). On the other hand, in vivo studies by Brittiberg et al reported opposite effects suggesting that FS-derived scaffolds were not suitable for osteochondrocal healing (10). While ambiguity remains over the application of FSs in articular cartilage repair, recent studies indicate that these biological adhesives possess unique osteoinductive properties (11). Furthermore, there is increasing evidence to suggest that FSs support the growth and migration of chondrocytes (12-15). Based on the collation of these and recent studies, the use of FSs as a component of autologous chondrocyte implantation (ACI) has now been advocated.

Thrombin, a coagulative serine protease, is an active ingredient of FSs. Thrombin is ubiquitously expressed at 
sites of vascular injury where it serves to accelerate the coagulation process via proteolytic cleavage of fibrinogen (16). In addition to its role in wound healing, thrombin has been shown to induce a variety of cellular responses including proliferation (17-21), migration (22-25) and survival $(26,27)$. These diverse biological effects are mediated through specific interaction(s) with cell surface receptors. Among the candidate thrombin receptors, members of the seven transmembrane $G$ protein-coupled protease activated-receptor (PAR) family (PAR-1, PAR-2, PAR-3, PAR-4) are perhaps the best characterised (28). Thrombin is known to activate intracellular signalling of PAR-1, 3 and 4 via cleavage of the extracellular N-terminal domain, which unmasks a 'tethered ligand' sequence which binds intramolecularly to a receptor domain thereby activating $G$ protein-coupled signal transduction pathways $(29,30)$. By comparison, PAR-2 is activated by trypsin and tryptase-associated proteases, but not thrombin (31-33). PAR-1, -2 and -4 can also be activated without proteolytic cleavage, using five to six amino-acid residue peptides corresponding to the new amino termini of the cleaved receptors (28).

The goal of this study was to assess the bioactive properties of commercial FS $\left(\right.$ Tissee ${ }^{\circledR}$ ), with particular emphasis on the thrombin component, on autologous human chondrocyte migration and proliferation in vitro. In addition, we examined the expression and localisation of PARs in cultured human chondrocytes. Our findings indicate that FS induces strong chemotactic and mitogenic responses in cultured chondrocytes. Furthermore, we provide evidence to suggest that these effects are mediated, at least in part, via thrombin-induced activation of PAR-1 signalling.

\section{Materials and methods}

Materials. Tisseel FS was purchased from Baxter AG (Vienna, Austria). Tissue culture reagents and molecular biology reagents were purchased from Life Technologies (Melbourne, Australia) and Stratagene (La Jolla, CA, USA) respectively. The Biotrak ${ }^{\circledR}$ cell proliferation ELISA system was purchased from Amersham Life Sciences (Buckinghamshire, UK). Synthetic agonist PAR peptides with amidated $\mathrm{C}$ termini (PAR-1, SFLLRN-NH 2 , TFLLRN-NH ${ }_{2}$; PAR-2, SLIGKV$\mathrm{NH}_{2}$; PAR-3, TFRGAP-NH $\mathrm{N}_{2}$; and PAR-4, GYPGQV-NH purity $>85 \%$ ) were synthesized by the Protein Facility, University of Western Australia, Perth, Australia. All other chemicals were purchased from Sigma-Aldrich (St. Louis, MO, USA) unless stated otherwise.

Cell culture. Cartilage biopsies obtained from healthy human patients were used as a source of chondrocytes. All patients consented and ethics approval was obtained through the University of Western Australia Human Research Ethics Committee. In brief, biopsies were mechanically disaggregated and then digested with $0.3 \%(\mathrm{w} / \mathrm{v})$ collagenase type II (Worthington Biochemical Corp., NJ, USA) at $37^{\circ} \mathrm{C}$ for $5-8 \mathrm{~h}$ with shaking to release chondrocytes. Following digestion, resulting chondrocyte suspensions were passed through a $100 \mu \mathrm{m}$ cell strainer (Becton Dickinson and Co., NJ, USA) before being cultured in a T75-culture flask containing DMEM F-12 media (Gibco, NY, USA) supplemented with 10\% (v/v) fetal calf serum (FCS) (Gibco), $292 \mu \mathrm{g} / \mathrm{ml} \mathrm{L-glutamine,}$ $10,000 \mathrm{U} / \mathrm{ml}$ penicillin $\mathrm{G}, 10,000 \mathrm{U} / \mathrm{ml}$ streptomycin sulfate, $25 \mu \mathrm{g} / \mathrm{ml}$ amphotericin B, and $50 \mu \mathrm{g} / \mathrm{ml}$ ascorbic acid. Cells were sub-cultured routinely as required per experimental condition.

In vitro MACI co-culture assay. To simulate the in vivo conditions following matrix-induced autologous chondrocyte implantation (MACI) (12), primary human chondrocytes $\left(5.0 \times 10^{6}\right.$ cells $\left./ \mathrm{ml}\right)$ were seeded onto a $1.5 \mathrm{~cm}^{2}$ type I/III collagen membrane (Matricel ${ }^{\circledR}$, Germany) in 6-well plates and left to attach for at least $24 \mathrm{~h}$. Following attachment, Tisseel FS (containing $500 \mathrm{U} / \mathrm{ml}$ thrombin) was applied to the cell-seeded surface of the membrane scaffold using the supplied duojector. The resulting membrane-cell-FS 'sandwiches' were then cultured in complete growth media for $12,24,48 \mathrm{~h}$, and 15 days to promote cell migration. Seeded collagen I/III membranes in the absence of FS served as controls. Migration patterns of chondrocytes towards the FS were scored either histologically or by phase-contrast light microscopy (Nikon Diaphot).

Histology. MACI-FS 'sandwiches' were carefully removed from culture medium and washed twice in $1 \mathrm{X}$ PBS before being fixed in ice-cold paraformaldehyde $(4 \% ; 15 \mathrm{~min})$ at room temperature. Following fixation, the 'sandwiches' were washed $3 \mathrm{x}$ with $1 \mathrm{X}$ PBS before undergoing routine paraffin processing and embedding. All samples were embedded in vertical orientation to the cutting plane so that both surfaces of the 'sandwiches' were displayed during tissue sectioning. Sections were cut (4-6 $\mu \mathrm{m})$, placed onto glass slides and then de-waxed (xylene: 2x 3-4 min; $100 \%$ ethanol: 2x 3-4 min; 95\% and $70 \%$ ethanol: $1 \times 3$ min each). All sections were stained with Gill's hematoxylin and eosin, mounted with Depex, and examined by light microscopy.

Proliferation assay. Cell proliferation was assayed by 5-bromo2'-deoxyuridine (BrdU) using a commercial available Biotrak cell proliferation ELISA system. Briefly, human chondrocytes $\left(5 \times 10^{3}\right.$ cells/well $)$ were cultured in $96-$ well plates in complete growth medium overnight. Following attachment, cells were washed twice with $1 \mathrm{X}$ phosphate-buffered-saline (PBS) and deprived of serum for an additional $24 \mathrm{~h}$ before the addition of thrombin $(0.1,0.5,1,10 \mathrm{U} / \mathrm{ml})$ or vehicle $\left(\mathrm{CaCl}_{2}, 40 \mathrm{mM}\right)$ in combination with serum-free DMEM F-12 for an additional 24-48 h. BrdU-labeling solution was then added to each well, and cells were re-incubated for an additional $16 \mathrm{~h}$. Time points (24 and $48 \mathrm{~h}$ ) were staggered so that addition of BrdU occurred on the same day. Cells were fixed, and incorporated BrdU was detected using immunoperoxidase and tetramethylbenzidine (TMB) according to the manufacturer's protocol. Absorbance was read at $450 \mathrm{~nm}$.

Reverse transcription (RT)-PCR. Total RNA was extracted from the primary human chondrocytes using RNAzol B according to the manufacturer's instructions (Tel-test, TX). cDNA was synthesised from $2 \mu \mathrm{g}$ of total RNA using the RETROscript $^{\mathrm{TM}}$ First-strand synthesis kit (Ambion). Primers against human PAR isoforms were designed based on published sequence data (34) and purchased from Genset 
Pacific Pty. Ltd., Australia. PAR-1, sense 5'-TGTGAACTGA TCATGTTTATG-3', anti-sense 5'-TTCGTAAGATAAGAG ATATGT-3' (PCR product, 708 bp); PAR-2, sense 5'-AGAA GCCTTATTGGTAAGGTT-3', anti-sense 5'-AACATCATG ACAGGTCGTGAT-3' (PCR product, 582 bp); PAR-3, sense 5'-CTGATACCTGCCATCTACCTCC-3, anti-sense 5'-AG AAAACTGTTGCCCACACC-3' (PCR product, $382 \mathrm{bp}$ ); PAR-4, sense 5'-ATTACTCGGACCCGAGCC-3', anti-sense 5'-TGTAAGGCCCACCCTTCTC-3' (PCR product, 392 bp). Amplification of $B$-actin, with the sense and anti-sense primer pair 5'-GGCTCTTCCAGCCTTCCTTCCT-3' and 5'-CACA GAGTACTTGCGCTCAGGAGG-3' (PCR product 240 bp), served as an internal loading control. PCRs were performed in $25 \mu \mathrm{l}$ reaction volumes containing $2 \mu \mathrm{l}$ of cDNA, $1 \mu \mathrm{l}$ of $5 \mathrm{mM}$ dNTPs, $2.5 \mu 1$ of $10 \mathrm{X}$ buffer (Boehringer Mannheim, Germany), $0.2 \mu 1$ of Taq DNA polymerase (Boehringer Mannheim) and water to $25 \mu \mathrm{l}$. Amplifications were performed in a DNA thermal cycler (model 2400; Perkin-Elmer). Cycling parameters were $94^{\circ} \mathrm{C}$ for $3 \mathrm{~min}$; 35 cycles: $94^{\circ} \mathrm{C}$ for $40 \mathrm{sec}$, annealing at $55^{\circ} \mathrm{C}$ (PAR-1 and GAPDH), $60^{\circ} \mathrm{C}$ (PAR-2) or $64^{\circ} \mathrm{C}$ (PAR-3 and PAR-4) for $40 \mathrm{sec}$, extension $72^{\circ} \mathrm{C}$ for $40 \mathrm{sec}$; and a final extension $72^{\circ} \mathrm{C}$ for $10 \mathrm{~min}$. PCR products were resolved on a $1.5 \%(\mathrm{w} / \mathrm{v})$ agarose gel containing ethidium bromide and visualised and photographed on a UV transilluminator.

Immunocytochemistry. Immunodetection of PARs was conducted on human chondrocytes cultured in 8-well chamber slides (LAB-Tek II; Nunc) according to methods previously described by Asokananthan et al (35). Briefly, upon reaching approximately $80 \%$ confluence, cells were washed twice with PBS before being fixed with $4 \%(\mathrm{v} / \mathrm{v})$ paraformaldehyde. Endogenous peroxidase activity was quenched by incubating chamber slides in $3 \%(\mathrm{v} / \mathrm{v}) \mathrm{H}_{2} \mathrm{O}_{2}$ for $5 \mathrm{~min}$, and non-specific binding was blocked by incubation in 10\% FCS in PBS for $1 \mathrm{~h}$. Cells were then incubated with primary antibodies raised against specific PAR isoforms: mouse monoclonal anti-human PAR-1 (ATAP2: sc-13503, Santa Cruz), mouse monoclonal anti-human PAR-2 (SAM11: sc-13504, Santa Cruz), rabbit polyclonal anti-PAR-3 (raised against peptide ${ }_{37}$ TLPIKT FRGAPPNSFEEFP $_{55}$; and rabbit polyclonal anti-PAR-4 (raised against peptide ${ }_{28} E_{D D S T P S L L P A P R G Y P G Q V}{ }_{39}$ ) (35). Following the addition of secondary antibodies (either biotinylated anti-mouse or anti-rabbit IgG), PAR expression was visualised using streptavidin peroxidase and diaminobenzidine (DAB). Incubation with either pre-immune serum or staining for the chondrocytic marker S-100 (rabbit polyclonal 18-0046, Zymed Laboratories Inc.) served as negative and positive controls respectively.

Immunolocalisation studies were performed essentially as previously outlined in Pavlos et al (36) using secondary antibodies (dilution of 1:1000): goat anti-rabbit or goat anti-mouse immunoglobulin $\mathrm{G}$ conjugated to Alexa Fluor 488 (Molecular Probes Inc.). Cell nuclei were visualised by counter-staining with Hoechst 33342 (1:10,000) (Molecular Probes Inc.). Detection of fluorochromes was carried out by confocal laser scanning microscopy (CLSM) (MRC-1000, Bio-Rad), equipped with a krypton-argon laser or argon ion laser coupled to an epifluorescence Nikon Diaphot 300 inverted microscope. Confocal sequences were collected as Bio-Rad PIC files and processed using Confocal Assistant 4.02. All images were collected under non-saturating conditions set up by the use of an output look-up table (LUT).

Intracellular $\mathrm{Ca}^{2+}$ mobilization. Intracellular calcium mobilization was measured fluorimetrically using Fura-2/AM (Molecular Probes, Eugene, OR, USA). Cells were trypsinised and seeded onto $10-\mathrm{mm}$ coverslips in $35-\mathrm{mm}$ culture dishes. Upon reaching confluence, cells were washed twice with freshly prepared physiological rodent saline (PRS, $138 \mathrm{mM}$ $\mathrm{NaCl}, 2.7 \mathrm{mM} \mathrm{KCl}, 1.8 \mathrm{mM} \mathrm{CaCl}_{2}, 1.06 \mathrm{mM} \mathrm{MgCl}_{2}, 12.4 \mathrm{mM}$ HEPES, $5.6 \mathrm{mM}$ glucose, and $1 \mathrm{mM}$ probenecid; $\mathrm{pH}$ 7.3) and loaded for $45 \mathrm{~min}$ at $\left(37^{\circ} \mathrm{C}\right)$ with Fura-2/AM $(3 \mu \mathrm{M})$ and $0.0125 \%$ F-127 (w/v) in PRS $\left(1 \times 10^{5}\right.$ cells $\left./ \mathrm{ml}\right)$. Following loading, cells were washed and incubated in the dark (30 min, room temperature). Coverslips were then removed and carefully placed into a heated bio-chamber $\left(37^{\circ} \mathrm{C}\right)$ attached to an inverted epifluorescence microscope (Nikon TE2000, Japan). Fluorescence emission (510 nm) at 340- and 380-nm excitation was measured using a spectrophotometer (Cairn, UK). Thrombin $(1 \mathrm{U} / \mathrm{ml})$ and PAR-1, 3 and 4 agonists $(400 \mu \mathrm{M})$ were added into the chamber following $1 \mathrm{~min}$ background recording and corresponding fluorescence emission ratios were recorded for $5 \mathrm{~min}$. The PAR-2 agonist was not assessed because of its known activation by trypsin and tryptase (31-33). All intracellular calcium concentrations were expressed as the ratio of emission following excitation of 340 and $380 \mathrm{~nm}$ respectively.

Statistical analyses. Unless stated otherwise, all data are expressed as mean \pm SEM. Statistical significance between means was determined by ANOVA or the Student's t-test using GraphPad Prism (GraphPad Software, San Diego, CA, USA). P-values $<0.01$ were considered significant.

\section{Results}

Fibrin sealant promotes chondrocyte migration in vitro. Our previous in vivo studies indicate that FS (Tissee ${ }^{\circledR}$ ) stimulates migration of autologous chondrocytes to osteochondral defects suggesting that the sealant possesses chemoattractive properties (15). In order to determine whether the observed chondrocytic migration was directly related to chemotactic activity of FS, or a subsidiary effect of the repair process in vivo, we sought to replicate MACI using an in vitro co-culture system. For this purpose, autologous human chondrocytes, grown on a type I/III collagen membrane (Matricel), were 'sandwiched' between FS and cultured in vitro for 12-48 h. Following incubation, the 'cell sandwiches' were fixed and the migratory activities assessed histologically. As shown in Fig. 1A, chondrocytic migration from the collagen scaffold toward the FS was observed as early as $12 \mathrm{~h}$ co-culture, although the majority of cells remained on the superficial surface of the collagen membrane, reminiscent to that of the control. At 24 and $48 \mathrm{~h}$ time points, substantial cell migration was evident, with no breaching of the FS surface observed. We also assessed chondrocytic migration in co-cultures incubated for up to 15 days. As shown in Fig. 1B, extensive migration of chondrocytes towards the FS-collagen interface is evident, with some cells clearly invading the fibrin matrix. Collectively, 
A

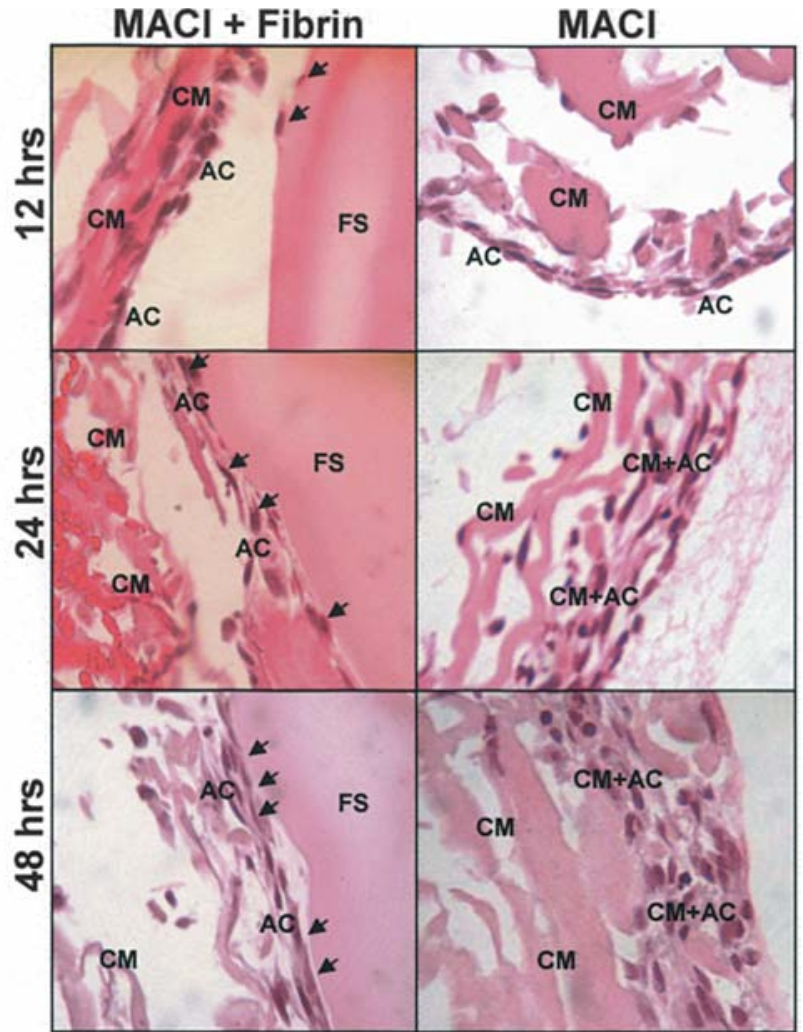

B

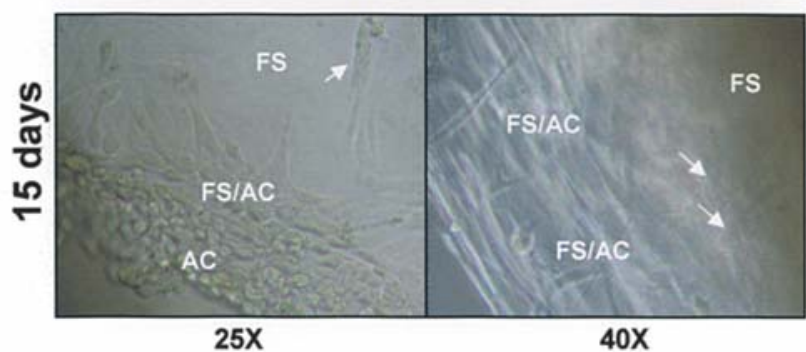

Figure 1. (A) Histology of chondrocyte migration from collagen membrane to FS from 12 to $48 \mathrm{~h}$. Chondrocyte migration from the collagen membrane towards the fibrin surface was seen after a 12-h culture (arrows). At 24 and $48 \mathrm{~h}$, aggregation of chondrocytes on the surface of the FS is clearly evident. In contrast, chondrocyte-seeded collagen membrane alone at 12, 24, and $48 \mathrm{~h}$ showed in-growth of chondrocytes into the collagen matrix of the membrane. All sections were stained with H\&E. Magnification, x25. (B) Chondrocyte migration and in-growth into FS at 15 days under phasecontrast microscopy. As seen at both $\mathrm{x} 25$ and $\mathrm{x} 40$ magnifications, chondrocyte in-growth was visualized within the FS (arrows). AC, autologous chondrocytes; CM, collagen membrane; FS, fibrin sealant.

these data corroborate the notion that FS promotes the migration of autologous chondrocytes.

Thrombin stimulates proliferation of human chondrocytes. Having established that FS stimulates chondrocytic migration we next asked the question whether the sealant also possessed mitogenic potential. Given that thrombin, the active constituent of FS, has been previously shown to induce proliferation of a variety of cell types including endothelial cells (37), neutrophils (38), and osteoblasts (20), we examined whether the thrombin component similarly influenced the proliferative capacity of articular chondrocytes. To this end, human chondrocytes were incubated with increasing concentrations of thrombin

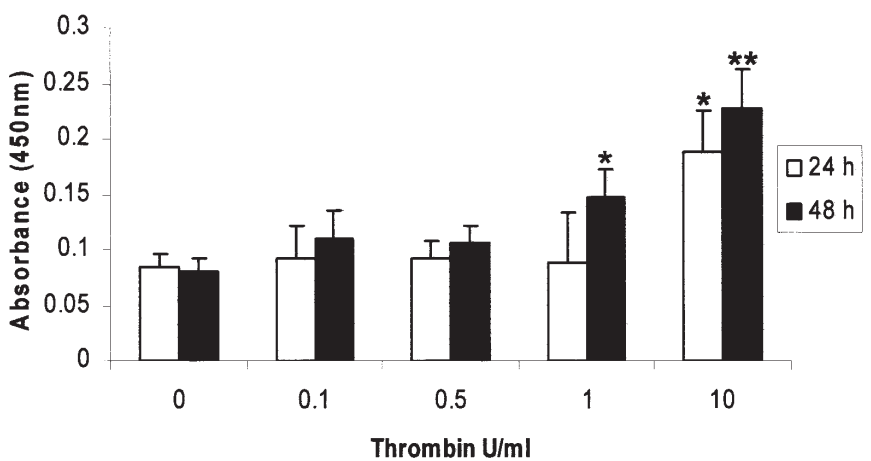

Figure 2. Proliferative response of human articular chondrocytes to different concentrations of thrombin. Chondrocytes were seeded onto 96-well plates, serum-starved for $24 \mathrm{~h}$ and then stimulated with varying concentrations of thrombin (0.1-10 U/ml) for an additional 24-48 h. Vehicle $\left(\mathrm{CaCl}_{2}, 40 \mathrm{mM}\right)$ served as a control. BrdU-incorporation as a parameter of proliferation was measured, and expressed as absorbance at $450 \mathrm{~nm}$. Data are expressed as mean \pm SEM $(n=6) .{ }^{*} \mathrm{p}<0.005 ;{ }^{* *} \mathrm{p}<0.0005$.

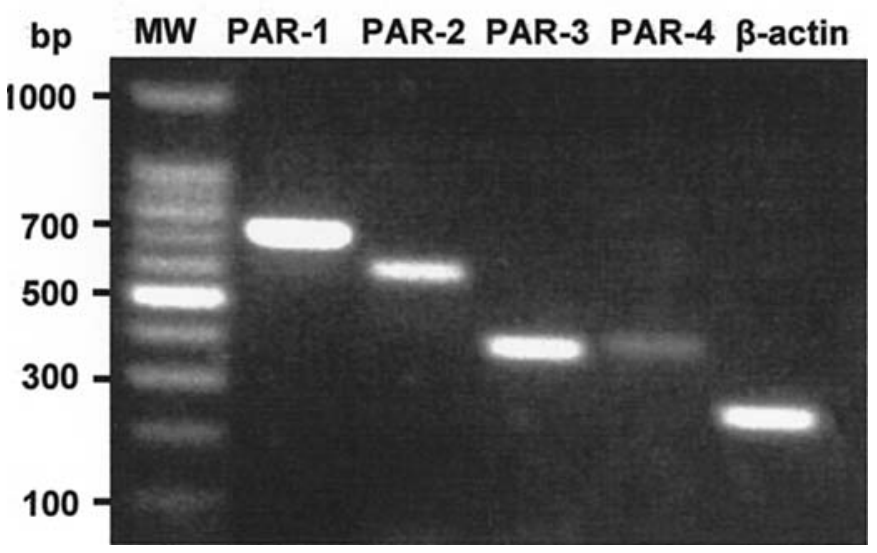

Figure 3. mRNA expression of PARs in human articular chondrocytes. Total RNA was isolated from cultured primary human chondrocytes and subjected to RT-PCR using PAR-isoform-specific primers. Reaction products were resolved by agarose gel $(1.5 \%)$ electrophoresis, stained with ethidium bromide, and visualized under a UV transilluminator. PAR-1 (708 bp) and PAR-3 (382 bp) are highly expressed in chondrocytes whereas PAR-2 (582 bp) and PAR-4 (392 bp) exhibit moderate to weak expression respectively. 3 -actin (240 bp) served as an internal loading control.

(0.1-10 U/ml) for 24 and $48 \mathrm{~h}$ time points and its effect on cell proliferation was assessed using an ELISA-based BrdU incorporation assay. As shown in Fig. 2, thrombin induced a marked increase in BrdU incorporation with maximal response observed at doses of $10 \mathrm{U} / \mathrm{ml}(24 \mathrm{~h}: \mathrm{p}<0.005 ; 48 \mathrm{~h}$ : $\mathrm{p}<0.0005)$. Significant proliferative activity was also detected in cells cultured in the presence of $1 \mathrm{U} / \mathrm{ml}$ thrombin, however only for the $48 \mathrm{~h}$ time point $(\mathrm{p}<0.005)$. On the other hand, lower concentrations of thrombin $(<1 \mathrm{U} / \mathrm{ml})$ failed to elicit any significant proliferative response. Comparable results were obtained using Alamar blue cell proliferation assays (data not shown). In all, these data indicate that the thrombin component of FS supports chondrocyte proliferation in vitro.

PAR-1 is the major PAR isoform expressed in human chondrocytes. Numerous studies indicate that thrombin elicits its biological responses via its interaction with, and subsequent activation of, PARs (28). Therefore, as an initial step towards 


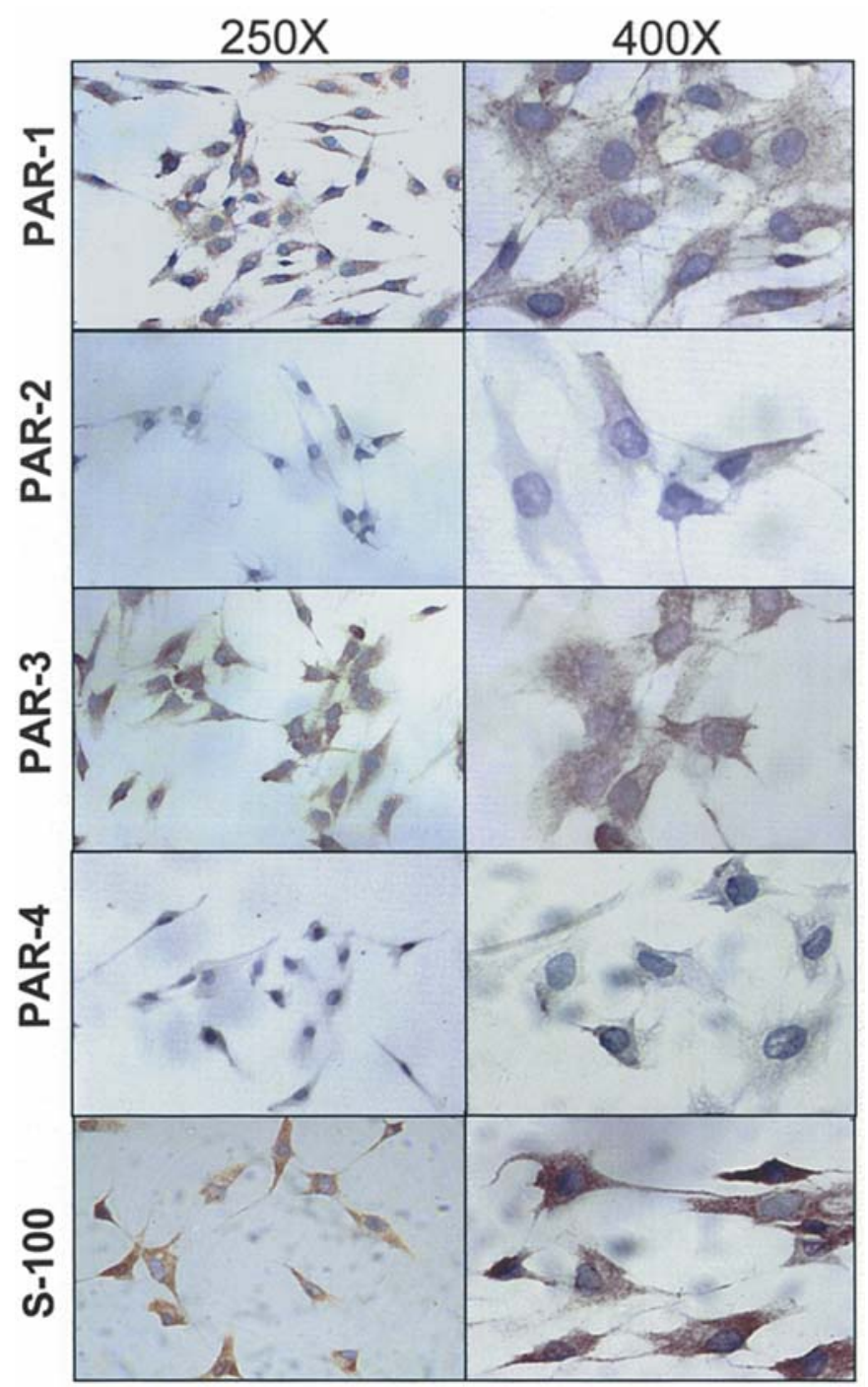

Figure 4. Immunocytochemical detection of PARs in cultured human chondrocytes. Strong expression of both PAR-1 and PAR-3 is evident in human chondrocytes. PAR-2 displayed moderate chondrocytic expression whilst negligible PAR-4 staining was detectable. Immunostaining for S-100 served as a positive marker for chondrocytes. Sections were viewed at x250 and x400 magnification.

elucidating the molecular mechanism(s) underlying thrombininduced chondrocyte proliferation, we examined the mRNA expression of PARs in chondrocytes by RT-PCR using isoform-specific primers. As shown in Fig. 3, PAR-1 and -3 mRNAs were highly expressed in cultured human chondrocytes. By comparison, PAR-2 and PAR-4 exhibited moderate to weak expression respectively.

To confirm the PCR data, we next assessed PAR protein expression levels by immunocytochemistry using a number of well-characterised PAR isoform-specific antisera (35) (Fig. 4). Consistent with the observed mRNA expression patterns, both PAR-1 and PAR-3 were strongly expressed in human chondrocytes, with PAR-1 exhibiting a slightly higher level of expression. On the other hand, PAR-2 displayed moderate staining whereas PAR-4 expression was detectable albeit weakly. Immunostaining for S-100 served as a positive control. Importantly, no appreciable staining was observed in the absence of PAR antibodies or when chondrocytes were treated with pre-immune serum at equivalent dilutions (data

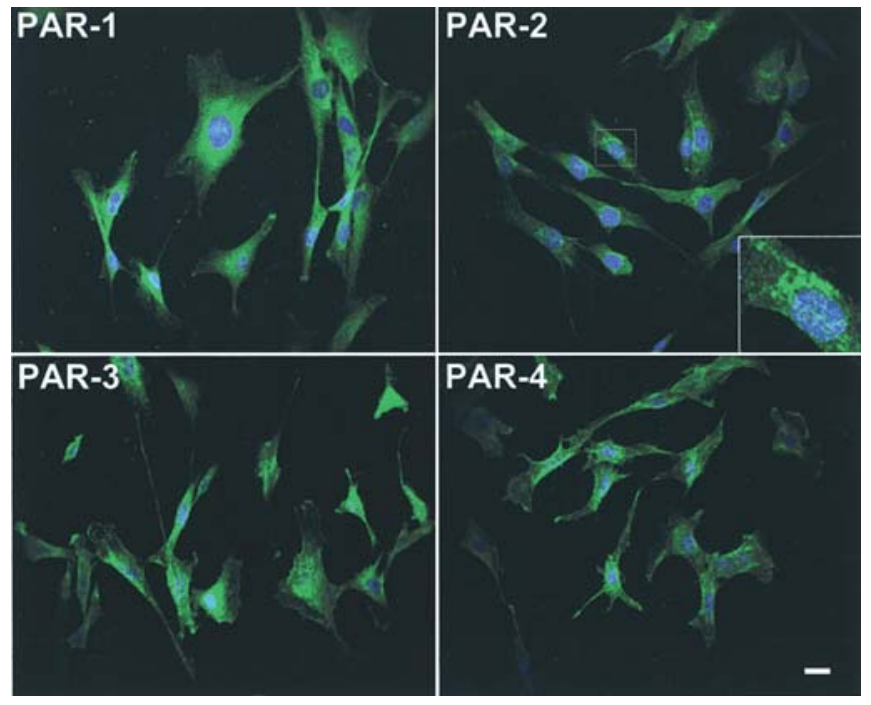

Figure 5. Subcellular localisation of PARs in human chondrocytes. Chondrocytes were grown on 8 -well chamber slides, fixed with $4 \%$ paraformaldehyde, and then immunostained for PAR isoforms (green). All slides were counter-stained with Hoescht 33342 to visualise nuclei (blue) and images were recorded by confocal microscopy. Marked staining of the plasma membrane and cytosol was detected for PAR-1, -3 and -4 . PAR-2 also shows plasma membrane staining as well as a sub-population of perinuclear vesicles (inset). Bar $=10 \mu \mathrm{m}$.

A

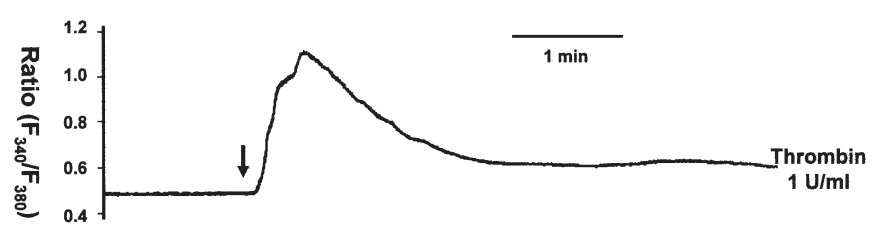

B

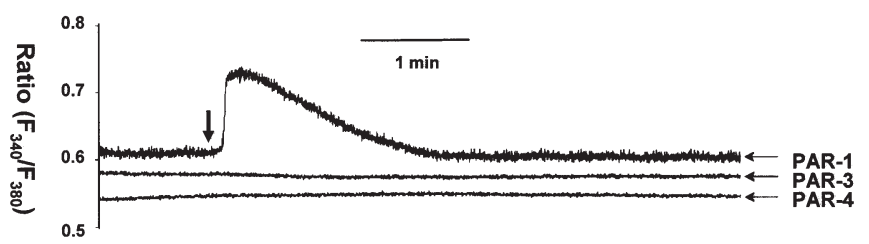

Figure 6. Intracellular calcium responses in human chondrocytes elicited by thrombin and PAR agonist peptides. Human chondrocytes were loaded with Fura-2/AM and incubated either with thrombin (1 U/ml) or PAR-1, -3 , and -4 agonist peptides at $400 \mu \mathrm{M}$. Thrombin (A) and PAR-1 agonist peptide SFLLRN-NH $\mathrm{N}_{2}$ (B) induced steep intracellular calcium elevations upon addition, but thrombin elevation did not return to baseline. All responses were measured over a 5 -min period and results were expressed as a fluorescence ratio $(340 / 380 \mathrm{~nm})$. Traces are representative of at least 5 independent experiments.

not shown). We also examined the subcellular localization of the PAR isoforms by confocal microscopy (Fig. 5). Whereas PAR-1, -3 and -4 isoforms were largely localized to the plasma membranes, with diffuse/reticular-like staining throughout the cytosol, PAR-2 predominantly associated with the plasma membrane and a population of small juxta-nuclear vesicular structures that were reminiscent of endosomes/lysosomes. Together, these data demonstrate that PARs are both differentially expressed and localized in human chondrocytes with 
PAR-1 being the major isotype expressed (PAR-1>PAR$3>$ PAR-2>PAR-4).

Thrombin and PAR-1 agonists induce $\left[\mathrm{Ca}^{2+}\right]_{i}$ influx in human chondrocytes. The primary upstream signalling pathway of the PARs includes intracellular calcium mobilization (39). Given that $\left[\mathrm{Ca}^{2+}\right]_{\mathrm{i}}$ mobilization have been well-documented to correlate with cell growth and proliferation (20) we hypothesised that the thrombin-induced proliferation might reflect changes in intracellular calcium signalling, possibly via interactions with PARs. To explore this notion, we monitored for changes in free cytosolic calcium concentration in response to thrombin and specific PAR agonist peptides using the $\mathrm{Ca}^{2+}$ indicator Fura-2. Thrombin at a concentration of $1 \mathrm{U} / \mathrm{ml}$ elicited a large $\left[\mathrm{Ca}^{2+}\right]_{\mathrm{i}}$ elevation within a few seconds (mean amplitude of fluorescence ratio transient: $0.65 \pm 0.09$; mean time to peak: $22.0 \pm 1.4 \mathrm{sec}, \mathrm{n}=8$ ) in approximately $75 \%$ of human chondrocytes examined, before gradually decaying (mean half decay time: $32.4 \pm 4.6 \mathrm{sec} ; \mathrm{n}=8$ ) to near-baseline level (Fig. 6A). Similarly, the PAR-1 agonist (SFLLRN-NH $2,400 \mu \mathrm{M}$ ) induced a significant and abrupt increase in intracellular $\left[\mathrm{Ca}^{2+}\right]$ in an equivalent proportion of human chondrocytes. However, the PAR-1-induced $\mathrm{Ca}^{2+}$ transients were significantly smaller in amplitude (mean amplitude of fluorescence ratio transient; $0.11 \pm 0.01 ; \mathrm{p}=0.0002, \mathrm{n}=6$ ) than that elicited by thrombin, but exhibited a steeper $\left[\mathrm{Ca}^{2+}\right]$ elevation phase (mean time to peak: $8.5 \pm 1.6 \mathrm{sec}, \mathrm{p}<0.0001, \mathrm{n}=6$ ). Nonetheless, the decay phase was comparable to the thrombin-induced $\mathrm{Ca}^{2+}$ transients (mean half decay time: $28.5 \pm 5.1 \mathrm{sec}, \mathrm{p}=0.58, \mathrm{n}=6$ ) (Fig. 6B). Similar responses were also observed using the TFLLRN-NH $\mathrm{N}_{2}$ PAR-1 agonist peptide (data not shown). In contrast to PAR-1 agonist peptides, the PAR-4 $(n=6)$ agonist peptide failed to elicit any visible $\mathrm{Ca}^{2+}$ response in human chondrocytes (Fig. 6B). Predictably, the PAR-3 agonist $(n=5)$ did not evoke calcium mobilization, consistent with its reported inability to activate PAR-3 and low-affinity to thrombin (40). Together, the analogies in $\left[\mathrm{Ca}^{2+}\right]_{\mathrm{i}}$ responses between thrombin and PAR-1 agonists hint that the thrombin-mediated effects on chondrocytes might act via PAR-1 signalling.

\section{Discussion}

The diverse application of FSs has been advocated by numerous studies from skin grafts through to attachment of osteochondral fragments $(2-4,41)$. We and others have previously reported the use of FSs as an adjunct for ACI to secure scaffold fixation and promote chondrogenesis $(12,13,15,42-44)$. Moreover, our in vivo studies indicate that chondrocytes migrate towards the FS during osteochondral repair suggesting that it may possess chemotactic potential. The purpose of this study was to assess the bioactivity of the commercial FS (Tisseel) on chondrocytes in vitro. Collectively, our data affirms that this FS not only promotes chondrocyte migration but also stimulates their proliferation.

Several bioactive components constitute commercial and autologous FSs including fibrinogen, Factor XIII, fibronectin, aprotinin and thrombin. Of these, thrombin has previously been shown to support the migration for a number of cell types including monocytes (45), macrophages (24), neutrophils (38), fibroblasts (23) and endothelial cells (46). In addition, during the course of this investigation, thrombin was shown to directly stimulate the migration of osteogenic cultures of primary bone marrow cells to bony wound sites (25). Our in vitro MACI co-culture experiments demonstrate that the FS Tisseel induces a strong chemoattractive response in primary human chondrocytes. Significant migratory activity of chondrocytes from the collagen scaffold towards the FS was observed within a 24-h co-culture; however, there was little evidence of chondrocytic cell in-growth into the glue, consistent with previous reports $(10,47)$. While we did note some marginal chondrocyte penetration into the FS at day 15, this probably represented the onset of sealant disintegration rather than a true reflection of cell in-growth. Clearly the precise FS factor(s) conferring these migratory effects remain to be clarified and will be the focus of future research. Nonetheless, given thrombin is the active component of commercial FS (Tisseel), together with its known chemotatic action; we speculate that this protease is the likely cause of the chondrocytic migration observed in this study.

In addition to promoting chemotaxis, thrombin has been shown to stimulate the proliferation of a variety of cell types $(20,26,27,48-50)$. Consistently, our dose- and time-coursedependent studies chondrocyte conclusively demonstrate that thrombin directly induces chondrocyte proliferation. Cellular proliferation was observed 24 -h post-stimulation with a maximum response at $10 \mathrm{U} / \mathrm{ml}$ thrombin, suggesting a threshold response concentration close to this point. Moreover, we demonstrate that this increase in cellular proliferation correlated with the mobilization of intracellular calcium.

It is well-established that changes in cellular calcium elicit several physiological sequelae, one of which is to stimulate cell mitotic activity. Thrombin has previously been shown to induce the proliferation of various cell types via the modulation of intracellular calcium (28). In osteoblastic cells, this calcium influx is mediated largely through the interaction of thrombin and activation of PARs suggesting that a similar mechanism may exist in ontogenically-related chondrocytes $(20,27,33,35)$. Indeed, our expression studies document, for the first time, the expression of PARs in human chondrocytes thus extending chondrocytes to the list of PAR-expressing cells. PAR-1 was identified as the predominant isotype followed by PAR-3, PAR-2 and PAR-4. This finding is in accordance with the expression patterns reported for other mesenchymal-lineage cells $(20,26,32,33)$.

Thrombin is known to activate PARs 1,3 and 4 in various cell types, whereas PAR-2 is activated by trypsin and tryptase $(20,33,51,52)$. Jenkins et al $(53)$ demonstrated in osteoblasts that intracellular calcium underwent a sustained rise after treatment with PAR-1-activating peptide, whereas thrombin caused a sharp peak followed by a rapid return to baseline. In contrast, our results show sustained $\left[\mathrm{Ca}^{2+}\right]_{\mathrm{i}}$ after thrombin treatment, and a sharp transient increase after PAR-1activating peptide treatment. It has been shown that ligand cross-reactivity exists in PARs whereby PAR-1-activating peptides are able to activate both PAR-1 and -2 (54). This is contradictory to the data reported here. It is possible that the elevated and sustained $\left[\mathrm{Ca}^{2+}\right]_{\mathrm{i}}$ response observed after thrombin treatment (in comparison to the PAR-1 agonist responses) is due to a number of factors. This discrepancy may be explained by either the presence of concurrent 
intermolecular PAR activation between the tethered ligand of PAR-1 and neighboring PARs (i.e. PAR-2) (55); combined thrombin activation of PARs 1,3 , and 4; downstream interplay between activated G-protein-coupled PAR pathways; or the possible presence of an unidentified chondrocyte thrombinsensitive PAR. Based on previous studies on sustained elevation of $\left[\mathrm{Ca}^{2+}\right]_{i}$ after PAR-2 treatment (33), the former two are considered the more likely possibilities.

The apparent lack of calcium sensitivity observed upon addition of the PAR-4 agonist peptide also implies that PAR-4 may not be crucial to chondrocyte physiology. This notion is supported by the comparatively weak expression levels of PAR-4 detected in human chondrocytes. Moreover, these findings are in accordance with calcium mobilization studies conducted with PAR-4 agonists in gingival fibroblasts which also exhibit strong PAR-1 and -3 but weak PAR-2 and -4 expression (56). Further studies will be required to unravel the precise roles of specific PAR isoforms in chondrocytes.

In summary, we demonstrate that the commercial FS Tisseel promotes the migration and proliferation of primary human chondrocytes. Moreover, we demonstrate that the thrombin component alone is sufficient to stimulate chondrocyte proliferation and elicit intracellular calcium mobilization. In addition, we document for the first time, the expression and localisation of PARs in chondrocytes and provide evidence to suggest that PAR-1 is the primary thrombin-acting PAR in chondrocytes and, thus, might account for the observed migratory and proliferative responses. This hypothesis will form the basis of more detailed studies in the future. Nonetheless, the data presented in this study endorse the use of FSs in autologous chondrocyte implantation for cartilage injury.

\section{Acknowledgements}

This study was supported by grants from the National Health and Medical Research Council (NHMRC) of Australia.

\section{References}

1. Jackson MR: Fibrin sealants in surgical practice: an overview. Am J Surg 182: 1S-7S, 2001.

2. Currie LJ, Sharpe JR and Martin R: The use of fibrin glue in skin grafts and tissue-engineered skin replacements: a review. Plast Reconstr Surg 108: 1713-1726, 2001.

3. Albala DM: Fibrin sealants in clinical practice. Cardiovasc Surg 11 (Suppl 1): 5-11, 2003.

4. Canonico $S$ : The use of human fibrin glue in the surgical operations. Acta Biomed Ateneo Parmense 74 (Suppl 2): 21-25, 2003.

5. Kaplonyi G, Zimmerman I, Frenyo AD, Farkas T and Nemes G: The use of fibrin adhesive in the repair of chondral and osteochondral injuries. Injury 19: 267-272, 1988.

6. Ono K, Shikata J, Shimizu K and Yamamuro T: Bone-fibrin mixture in spinal surgery. Clin Orthop Relat Res 275: 133-139, 1992.

7. Homminga GN, Bulstra SK, van der Linden AJ and Bouwmeester PS: Perichondral grafting for cartilage lesions of the knee. J Bone Joint Surg Br 72: 1003-1007, 1990.

8. Homminga GN, Buma P, Koot HW, van der Kraan PM and van den Berg WB: Chondrocyte behavior in fibrin glue in vitro. Acta Orthop Scand 64: 441-445, 1993.

9. Hendrickson DA, Nixon A J, Erb HN and Lust G: Phenotype and biological activity of neonatal equine chondrocytes cultured in a three-dimensional fibrin matrix. Am J Vet Res 55: 410-414, 1994.
10. Brittberg M, Sjogren-Jansson E, Lindahl A and Peterson L: Influence of fibrin sealant (Tisseel) on osteochondral defect repair in the rabbit knee. Biomaterials 18: 235-242, 1997.

11. Abiraman S, Varma HK, Umashankar PR and John A: Fibrin glue as an osteoinductive protein in a mouse model. Biomaterials 23: 3023-3031, 2002.

12. Cherubino P, Grassi FA, Bulgheroni P and Ronga M: Autologous chondrocyte implantation using a bilayer collagen membrane: a preliminary report. J Orthop Surg 11: 10-15, 2003.

13. Neovius EB and Kratz G: Tissue engineering by cocultivating human elastic chondrocytes and keratinocytes. Tissue Eng 9: 365-369, 2003.

14. Visna P, Pasa L, Adler J, Folvarsky J and Horky D: Treatment of deep chondral defects of the knee using autologous chondrocytes cultured on a support - preparation of the cartilage graft. Acta Chir Orthop Traumatol Cech 70: 350-355, 2003.

15. Willers C, Chen J, Wood D, Xu J and Zheng MH: Autologous chondrocyte implantation with collagen bioscaffold for the treatment of osteochondral defects in rabbits. Tissue Eng 11: 1065-1076, 2005.

16. Powers JC and Kam CM: Synthetic Substrates and Inhibitors of Thrombin. Plenum Press, New York, pp117-158, 1992.

17. Tani K, Yasuoka S, Ogushi F, Asada, K, Fujisawa K, Ozaki T, Sano $N$ and Ogura T: Thrombin enhances lung fibroblast proliferation in bleomycin-induced pulmonary fibrosis. Am J Respir Cell Mol Biol 5: 34-40, 1991

18. Borrelli V, Sterpetti AV, Coluccia P, Randone B, Cavallaro A, Santoro D'Angelo L and Cucina A: Bimodal concentrationdependent effect of thrombin on endothelial cell proliferation and growth factor release in culture. J Surg Res 100: 154-160, 2001.

19. Kaufmann K and Thiel G: Epidermal growth factor and thrombin induced proliferation of immortalized human keratinocytes is coupled to the synthesis of Egr-1, a zinc finger transcriptional regulator. J Cell Biochem 85: 381-391, 2002.

20. Abraham, LA and MacKie EJ: Modulation of osteoblast-like cell behavior by activation of protease-activated receptor-1. J Bone Miner Res 14: 1320-1329, 1999.

21. Song SJ, Pagel CN, Campbell TM, Pike RN and Mackie EJ: The role of protease-activated receptor- 1 in bone healing. Am J Pathol 166: 857-868, 2005.

22. Bar-Shavit R, Kahn A, Fenton JW and Wilner GD: Chemotactic response of monocytes to thrombin. J Cell Biol 96: 282-285, 1983.

23. Brown LF, Lanir N, McDonagh J, Tognazzi K, Dvorak AM and Dvorak HF: Fibroblast migration in fibrin gel matrices. Am J Pathol 142: 273-283, 1993.

24. Ciano PS, Colvin RB, Dvorak AM, McDonagh J and Dvorak HF: Macrophage migration in fibrin gel matrices. Lab Invest 54: 62-70, 1986.

25. Karp JM, Tanaka TS, Zohar R, Sodek J, Shoichet, MS, Davies JE and Stanford WL: Thrombin mediated migration of osteogenic cells. Bone 37: 337-348, 2005.

26. Chinni C, De Niese MR, Tew DJ, Jenkins AL, Bottomley SP and Mackie EJ: Thrombin, a survival factor for cultured myoblasts. J Biol Chem 274: 9169-9174, 1999.

27. Pagel CN, De Niese MR, Abraham LA, Chinni C, Song SJ, Pike RN and Mackie EJ: Inhibition of osteoblast apoptosis by thrombin. Bone 33: 733-743, 2003.

28. Mackie EJ, Pagel CN, Smith R, De Niese MR, Song SJ and Pike RN: Protease-activated receptors: a means of converting extracellular proteolysis into intracellular signals. IUBMB Life 53: 277-281, 2002.

29. Ishihara H, Connolly AJ, Zeng D, Kahn ML, Zheng YW, Timmons C, Tram T and Coughlin SR: Protease-activated receptor 3 is a second thrombin receptor in humans. Nature 386 : 502-506, 1997.

30. Vu TK, Hung DT, Wheaton VI and Coughlin SR: Molecular cloning of a functional thrombin receptor reveals a novel proteolytic mechanism of receptor activation. Cell 64: 1057-1068, 1991.

31. Akers IA, Parsons M, Hill MR, Hollenberg MD, Sanjar S, Laurent GJ and McAnulty RJ: Mast cell tryptase stimulates human lung fibroblast proliferation via protease-activated receptor-2. Am J Physiol Lung Cell Mol Physiol 278: L193-L201, 2000 .

32. Chinni C, De Niese MR, Jenkins AL, Pike RN, Bottomley SP and Mackie EJ: Protease-activated receptor- 2 mediates proliferative responses in skeletal myoblasts. J Cell Sci 113: 4427-4433, 2000 . 
33. Abraham LA, Chinni C, Jenkins AL, Lourbakos A, Ally N, Pike RN and Mackie EJ: Expression of protease-activated receptor-2 by osteoblasts. Bone 26: 7-14, 2000.

34. Brass LF and Molino M: Protease-activated G protein-coupled receptors on human platelets and endothelial cells. Thromb Haemost 78: 234-241, 1997.

35. Asokananthan N, Graham PT, Fink J, Knight DA, Bakker AJ, McWilliam AS, Thompson PJ and Stewart GA: Activation of protease-activated receptor (PAR)-1, PAR-2, and PAR-4 stimulates IL-6, IL-8, and prostaglandin E2 release from human respiratory epithelial cells. J Immunol 168: 3577-3585, 2002.

36. Pavlos NJ, Xu J, Riedel D, Yeoh JS, Teitelbaum SL, Jahn R, Papadimitriou JM, Ross FP and Zheng MH: Rab3D regulates a novel vesicular trafficking pathway that is required for osteoclastic bone resorption. Mol Cell Biol 25: 5253-5269, 2005.

37. Wang HS, Li F, Runge MS and Chaikof EL: Endothelial cells exhibit differential chemokinetic and mitogenic responsiveness to alpha-thrombin. J Surg Res 68: 5253-5264, 1997.

38. Jenkins AL, Howells GL, Scott E, Le Bonniec BF, Curtis MA and Stone SR: The response to thrombin of human neutrophils: evidence for two novel receptors. J Cell Sci 108: 3059-3066, 1995.

39. Dery O, Corvera CU, Steinhoff M and Bunnett NW: Proteinaseactivated receptors: novel mechanisms of signaling by serine proteases. Am J Physiol 274: C1429-C1452, 1998.

40. Owen WG: PAR-3 is a low-affinity substrate, high affinity effector of thrombin. Biochem Biophys Res Commun 305: 166-168, 2003.

41. Shah MA, Ebert AM and Sanders WE: Fibrin glue fixation of a digital osteochondral fracture: case report and review of the literature. J Hand Surg [Am] 27: 464-469, 2002.

42. Hutmacher DW, Goh JC and Teoh SH: An introduction to biodegradable materials for tissue engineering applications. Ann Acad Med Singapore 30: 183-191, 2001.

43. Kaplonyi G, Zimmermann I, Farkas T and Viola T: Repair of cartilage injuries and osteochondral fractures with fibrin glue. Orv Hetil 125: 2237-2243, 1984.

44. Visna P, Pasa L, Hart R, Kocis J, Cizmar I and Adler J: Treatment of deep chondral defects of the knee using autologous chondrocytes cultured on a support - results after one year. Acta Chir Orthop Traumatol Cech 70: 356-362, 2003.

45. Bar-Shavit Z, Teitelbaum SL, Reitsma P, Hall A, Pegg LE, Trial J and Kahn AJ: Induction of monocytic differentiation and bone resorption by 1,25-dihydroxyvitamin D3. Proc Natl Acad Sci USA 80: 5907-5911, 1983.
46. Nehls V and Herrmann R: The configuration of fibrin clots determines capillary morphogenesis and endothelial cell migration. Microvasc Res 51: 347-364, 1996.

47. Gille J, Meisner U, Ehlers EM, Muller A, Russlies M and Behrens P: Migration pattern, morphology and viability of cells suspended in or sealed with fibrin glue: a histomorphologic study. Tissue Cell 37: 339-348, 2005.

48. Frost A, Jonsson KB, Ridefelt P, Nilsson O, Ljunghall S and Ljunggren $\mathrm{O}$ : Thrombin, but not bradykinin, stimulates proliferation in isolated human osteoblasts, via a mechanism not dependent on endogenous prostaglandin formation. Acta Orthop Scand 70: 497-503, 1999 .

49. De Niese MR, Chinni C, Pike RN, Bottomley SP and Mackie EJ: Dissection of protease-activated receptor-1-dependent and -dependent responses to thrombin in skeletal myoblasts. Exp Cell Res 274: 149-156, 2002.

50. Gruber R, Jindra C, Kandler B, Watzak G, Fischer MB and Watzek G: Proliferation of dental pulp fibroblasts in response to thrombin involves mitogen-activated protein kinase signalling. Int Endod J 37: 145-150, 2004.

51. Corvera CU, Dery O, McConalogue K, Gamp P, Thoma M, Al-Ani B, Caughey GH, Hollenberg MD and Bunnett NW: Thrombin and mast cell tryptase regulate guinea-pig myenteric neurons through proteinase-activated receptors- 1 and -2 . J Physiol 517: 741-756, 1999.

52. Molino M, Barnathan ES, Numerof R, Clark J, Dreyer M, Cumashi A, Hoxie JA, Schechter N, Woolkalis M and Brass LF: Interactions of mast cell tryptase with thrombin receptors and PAR-2. J Biol Chem 272: 4043-4049, 1997.

53. Jenkins AL, Bootman MD, Berridge MJ and Stone SR: Differences in intracellular calcium signaling after activation of the thrombin receptor by thrombin and agonist peptide in osteoblast-like cells. J Biol Chem 269: 17104-17110, 1994.

54. Blackhart BD, Emilsson K, Nguyen D, Teng W, Martelli AJ, Nystedt S, Sundelin J and Scarborough RM: Ligand crossreactivity within the protease-activated receptor family. J Biol Chem 271: 16466-16471, 1996.

55. O'Brien PJ, Molino M, Kahn M and Brass LF: Protease-activated receptors: theme and variations. Oncogene 20: 1570-1581, 2001 .

56. Tanaka N, Morita T, Nezu A, Tanimura A, Mizoguchi I and Tojyo Y: Thrombin-induced $\mathrm{Ca}^{2+}$ mobilization in human gingival fibroblasts is mediated by protease-activated receptor-1 (PAR-1). Life Sci 73: 301-310, 2003. 